\title{
Dissection of Trichoderma longibrachiatum-induced defense in onion (Allium cepa L.) against Fusarium oxysporum f. sp. cepa by target metabolite profiling
}

Mostafa Abdelrahman $^{\mathrm{a}}$, Fatma Abdel-Motaal ${ }^{\mathrm{b}}$, Magdi El-Sayed ${ }^{\mathrm{b}}$, Sudisha Jogaiah ${ }^{\mathrm{c}}$, Masayoshi Shigyo $^{\mathrm{a}}$, Shin-ichi Ito ${ }^{\mathrm{d}, *}$, Lam-Son Phan $\operatorname{Tran}^{\mathrm{e}}{ }^{\mathrm{e}}$

a The United Graduate School of Agricultural Sciences, Tottori University, 4-101 KoyamaMinami, Tottori 680-8553, Japan

${ }^{\mathrm{b}}$ Botany Department Faculty of Science, Aswan University, Aswan 81528, Egypt

${ }^{\mathrm{c}}$ Plant Healthcare and Diagnostic Center, PG Department of Biotechnology and Microbiology, Karnatak University, Dharwad 580 003, Karnataka, India

${ }^{\mathrm{d}}$ Laboratory of Molecular Plant Pathology, Department of Biological and Environmental Sciences, Faculty of Agriculture, Yamaguchi University, Yamaguchi, Japan

${ }^{\mathrm{e}}$ Plant Abiotic Stress Research Group \& Faculty of Applied Sciences, Ton Duc Thang University, Ho Chi Minh City, 70000, Vietnam; Signaling Pathway Research Unit, RIKEN Center for Sustainable Resource Science, 1-7-22, Suehiro-cho, Tsurumiku, Yokohama 230-0045, Japan

\section{*Corresponding authors:}

Shin-ichi Ito; Laboratory of Molecular Plant Pathology, Department of Biological and Environmental Sciences, Faculty of Agriculture, Yamaguchi University, Yamaguchi, Japan. Fax: +81083933 5820. E-mail address: shinsan@yamaguchi-u.ac.jp.

Lam-Son Phan Tran; Plant Abiotic Stress Research Group \& Faculty of Applied Sciences, Ton Duc Thang University, Ho Chi Minh City, 70000, Vietnam; Signaling Pathway Research Unit, RIKEN Center for Sustainable Resource Science, 1-7-22, Suehiro-cho, Tsurumiku, Yokohama 230-0045, Japan. Fax: +81 45503959. E-mail address: sontran@tdt.edu.vn; son.tran@riken.jp 


\begin{abstract}
Trichoderma spp. are versatile opportunistic plant symbionts that can cause substantial changes in the metabolism of host plants, thereby increasing plant growth and activating plant defense to various diseases. Target metabolite profiling approach was selected to demonstrate that Trichoderma longibrachiatum isolated from desert soil can confer beneficial agronomic traits to onion and induce defense mechanism against Fusarium oxysporum f. sp. cepa (FOC), through triggering a number of primary and secondary metabolite pathways. Onion seeds primed with Trichoderma T1 strain displayed early seedling emergence and enhanced growth compared with Trichoderma T2-treatment and untreated control. Therefore, T1 was selected for further investigations under greenhouse conditions, which revealed remarkable improvement in the onion bulb growth parameters and resistance against FOC. The metabolite platform of T1primed onion (T1) and T1-primed onion challenged with FOC (T1+FOC) displayed significant accumulation of 25 abiotic and biotic stress-responsive metabolites, representing carbohydrate, phenylpropanoid and sulfur assimilation metabolic pathways. In addition, T1- and T1+FOCtreated onion plants showed discrete antioxidant capacity against 1,1 -diphenyl-2-picrilhydrazyl (DPPH) compared with control. Our findings demonstrated the contribution of $T$. longibrachiatum to the accumulation of key metabolites, which subsequently leads to the improvement of onion growth, as well as its resistance to oxidative stress and FOC.
\end{abstract}

Key words: Antioxidant; Metabolite profiling; Onion; Plant growth promoting fungi; Secondary metabolites 


\section{Introduction}

Onions (Allium cepa L.) are the third most economically important crop worldwide with a total production of 85 million tonnes per year [1]. Its consumption as food or ethnomedicine is mainly attributed to the cuisinal and medicinal properties, including antiasthmatic, antichlolesterolemic and antimicrobial [2-4]. However, a large portion of the world's onion producing areas (e.g., Mediterranean to semiarid climates) are located in regions that currently suffer, or are expected to encounter in future environmental stresses [1]. Unfavorable environmental growth factors, such as drought, salinity, heat, nutritional imbalance and diseases, constitute a major limitation to onion production [5], which is estimated to increase drastically due to global climate change, affecting the agricultural system in general and onion production, yield, quality and market value of the crop in particular [5-7]. In addition, the excessive uses of chemical fertilizers and pesticides in agriculture to maximize crop productivity are becoming more restricted due to environmental and health concerns, adding further pressure on agricultural systems [8]. These challenges have led to research into alternative sustainable cropping practices, with a strong focus on exploiting beneficial organisms to enhance crop fitness and increase stress tolerance.

Plant growth promoting fungi (PGPFs) and rhizobacteria (PGPRs) have been considered more natural and environmentally acceptable alternatives to traditional agricultural practices for managing the disease and growth parameters in a number of vegetable crops [9-11]. Among PGPFs, most commonly used in agriculture are the species of Trichoderma which are known to stimulate plant growth by increasing water and mineral uptake, notably that of phosphate, as well as suppressing plant diseases [12,13]. Root colonization by Trichoderma spp. causes substantial changes to the plant proteome and metabolome, resulting in improvements of the crop productivity and tolerability to abiotic and biotic stresses [13,14]. However, a lot of attention has been paid only to the physiological and biological reprogramming of plants triggered by dynamic interactions with Trichoderma spp., such as in chili (Capsicum annuum L.) [15], sunflower (Helianthus annuus L.) [16], tomato (Solanum lycopersicum L.) [9] and cucumber (Cucumis sativus L.) [17]. Most of these studies have focused on the phenotypic, enzymatic and molecular features underlying Trichoderma-plant-pathogen interactions. Little effort has been invested in the metabolome changes in the host plants pretreated with Trichoderma spp. under biotic stresses. Metabolite profiling aimed at a quantitative assessment of a predefined number of target metabolites with diverse functional properties can be used to acquire comprehensive information 
and a functional screen of the plant responses to PGPFs. Identifying the stress-responsive metabolites provides a valuable tool to advance our understanding of crop development and adaption to different environmental stresses [18]. In addition, Trichoderma-beneficial effects differ with respect to plant genotype, fungal strain and applied concentrations $[17,19]$. These create a necessity to broaden our host plant database, as well as the applied fungal strains to get a more comprehensive overview of the responsive mechanisms.

The metabolic architecture underlying the T. longibrachiatum-onion-Fusarium oxysporum f. sp. сера (FOC) interactions has not been reported. Therefore, the aim of the present study was to demonstrate that $T$. longibrachiatum can confer beneficial agronomic traits to onion and induce onion defense mechanism by stimulating primary and secondary metabolic pathways. An in-depth biochemical and molecular characterizations of the two T. longibrachiatum isolates were conceded. The impact of the T. longibrachiatum treatments on the onion vegetative growth parameters under normal conditions from seedling (seedling weight and height) up to 6-monthold stage (bulb size, weight, plant height, dry matter and moisture content) was monitored. Because a common factor among abiotic and biotic stresses is oxidative stress [7], to understand the intricate metabolic processes involved in Trichoderma-onion-FOC interactions, we first selected 38 metabolites representing primary and secondary metabolic classes (e.g., metabolism of carbohydrates, phenolics, organic acids, amino acids, cysteine sulfoxides and pigments), which may play important roles in onion stress responses [7,20,21]. The absolute concentrations of these 38 metabolites in the Trichoderma strain T1-primed onion (T1), T1-primed onion challenged with FOC (T1+FOC) and control were accurately quantified using HPLC and spectrophotometric analyses. T1- and T1+FOC-treated onion bulbs were investigated in vitro for its role in the regulation of antioxidant machinery of the onion bulb extract which is an important factor in nutrition, food quality and plant defense. The obtained data can foresee tremendous improvements in our understanding of the mechanisms underlying the production and function of hug variety of plant metabolites during Trichoderma-onion-FOC interactions. From a nutritional point of view, these Trichoderma-onion-induced metabolites are important for human health either as food, flavor, cosmetics or drugs, thereby adding new values for the indispensable roles of T. longibrachiatum in onion food quality and nutrition. 


\section{Materials and methods}

\subsection{Chemicals and reagents}

Analytical grade standards and reagents were purchased either from NacalaiTesque, Inc. (Kyoto, Japan), Wako Pure Chemical Industries Ltd. (Osaka, Japan), Somatech Center House Food Corporation (Tokyo, Japan), Waters Corporation (Milford, USA), or Sigma-Aldrich Co. (St. Louis, USA). Millipore-grade water was used in all experiments. The Fusarium oxysporum f. sp сера (FOC) strains TA (AB936618) and AF22 (AB936567) were obtained from Yamaguchi University.

\subsection{Isolation of PGPFs from the desert soil and Nile river}

Soil samples collected from extremely hot desert site and Nile water samples obtained from Aswan governorate, were subjected to 10 times serial dilution technique. $100 \mu \mathrm{l}$ of desert soil or Nile water diluted samples were spread separately on potato dextrose agar (PDA) plate that was then incubated at $25^{\circ} \mathrm{C} \pm 2$ for 7 days. Several fungal species were obtained, out of which two PGPF Trichoderma isolates coded T1 and T2 were assessed based on morphological microscopic examination. Pathogenicity test was carried out using cyclohexamide media [22].

\subsection{Biochemical and molecular characterizations of the PGPF isolates}

\subsubsection{Assay for PGPF thermal stability}

PDA plates $(9 \mathrm{~cm})$ inoculated with $0.5 \mathrm{~cm}$ mycelial disc of isolates $\mathrm{T} 1$ and T2 were incubated at different temperatures $20,25,30,35,40,45,50$ and $55^{\circ} \mathrm{C}$. The fungal radial growth was measured and recorded after 7 days.

\subsubsection{Assay for root colonization}

Root colonization by T1 and T2 strains was assessed according to Shivanna et al. [23].

\subsection{3. $\mathrm{pH}$ change}

One $\mathrm{ml}$ of spore suspension $\left(1 \times 10^{7}\right.$ spores $\left.\mathrm{ml}^{-1}\right)$ of each PGPF isolates was inoculated in $250 \mathrm{ml}$ conical flask containing $100 \mathrm{ml}$ sterile Pikovskaya (PVK) broth (pH 7.0) and incubated at $25 \pm$ $2{ }^{\circ} \mathrm{C}$ under shaking for 21 days. The changes in $\mathrm{pH}$ were recorded after one, two and three weeks. 


\subsubsection{Quantitative analysis of $P$ solubilization}

Phosphorus content in PVK broth was determined according to Watanabe and Olsen [24].

\subsubsection{Determination of indole 3 acetic acid (IAA)}

IAA induction using potato dextrose broth (PDB) supplemented with one mg tryptophan $\mathrm{ml}^{-1}$ was determined according to Gordon and Weber [25].

\subsubsection{Molecular characterization of the PGPF isolates}

PGPF genomic DNA was extracted by Takara DNA extraction kit (Takara Shuzo Co. LTD. Japan) and amplified using ITS1-F and ITS4-R primers: (ITS1-F: 5'

CCGTAGGTGAACCTGCGG-3' and ITS4-R: 5'-TCCTCCGCTTATTGATATGC-3'). PCR was performed using a thermal cycler TP600 (Takara Bio, Shiga, Japan) with a $20 \mu \mathrm{l}$ reaction according to the method described by Sudisha et al. [9]. Sequence assembly was performed with Finch TV version 1.4.0 (www.geospiza.com)

\subsection{Dual culture assay}

The two PGPF isolates T1 and T2 were evaluated for their antagonistic nature against FOC TA and AF22 strains in dual culture tests according to Coşkuntuna and Özer [21].

\subsection{Assay of PGPF effect on seed germination and seedling growth}

Onion seeds were surface sterilized with $0.3 \%$ sodium hypochloride for $3 \mathrm{~min}$, then rinsed in sterile distilled water (SDW) for $10 \mathrm{~min}$. Sterilized seeds in 3 biological replicates (20 seeds/replicate) were treated with $25 \mathrm{ml}$ (for each biological replicate of seeds) conidial spores suspension $\left(1 \times 10^{7}\right)$ of each PGPF isolate and SDW (control) at $25 \pm 2{ }^{\circ} \mathrm{C}$ for $6 \mathrm{~h}$. Treated seeds were then plated equidistantly on SDW moistened blotter discs placed in glass Petri plates and incubated in growth chamber at $25 \pm 2{ }^{\circ} \mathrm{C}$ with $12 \mathrm{~h} \mathrm{light/dark} \mathrm{photoperiod.} \mathrm{Seedling} \mathrm{emergence}$ was observed daily and germination percentage was calculated. Onion seeds primed as described above were sown in plastic pots containing sterilized mixture (1:1 v/v), of peat moss (and sterilized sand. Seedlings were grown in the growth chamber at $25 \pm 2{ }^{\circ} \mathrm{C}$ for one month. Seedling weight and height of T1, T2 and SDW treatments were measured accordingly. 


\subsection{Assay of PGPF effect on onion crop improvement}

One month-old primed seedlings were transferred into earthen pots filled with mixture of peat moss, vermiculite and sand $(1: 1: 1, \mathrm{v} / \mathrm{v})$. The soil was treated with $\mathrm{T} 1$ conidial spores suspension (250 $\mathrm{ml}$ of $1 \times 10^{7}$ ) before transplanting. The pots were arranged in a randomized complete block under greenhouse conditions. Soil treatment with T1 conidial spores suspension was repeated every month. Six month-old onion plants were randomly selected and the bulb size, weight and plant height were measured. For determination of dry matter and moisture content $5 \mathrm{~g}$ of bulb was dried in an oven at $70{ }^{\circ} \mathrm{C}$ for $48 \mathrm{~h}$. The percentage of bulb dry matter and moisture content were measured according to the following equations.

$\%$ Dry matter $=($ Bulb dry weight $/$ Bulb fresh weight $) \times 100$

$\%$ Moisture content $=[($ Bulb fresh weight-Bulb dry weight $) /$ Bulb fresh weight $)] \times 100$

\subsection{Plant inoculation}

Six-month-old T1-treated onion plants were challenged to infection with $50 \mathrm{ml}$ spore suspension of FOC TA $\left(1 \times 10^{7}\right)$ for $30 \mathrm{~min}$ by root deep inoculation at $27^{\circ} \mathrm{C}$. T1+FOC-treated onion plants were transferred into earthen pots filled with mixture of peat moss, vermiculite and sand (1:1:1, v/v) pre-infested with FOC TA strain. Bulb and leaf samples were separately harvested after $24 \mathrm{~h}$ post-inoculation for metabolites analysis.

In a separate experiment, the plant materials under the above conditions were kept for 3 weeks. The disease severity on the onion bulbs was recorded in T1-primed onion plants challenged with FOC strain TA (T1+FOC), SDW-treated onion plants challenged with FOC TA strain (FOC), and SDW-treated onion plants alone (Control). The disease severity percentage was based on scale 0 -100, where $0=$ healthy and $100=$ extremely infected.

\subsection{Metabolites analyses}

\subsubsection{Sample preparation and extraction for metabolites analyses}

Three independent biological replications of six month-old T1-, T1+FOC- and SDW-treated onion plants were randomly selected. Onion bulb and leaf samples (5 g each) were separately extracted with $50 \mathrm{ml}$ of $70 \%$ hot ethanol according to Abdelrahman et al., [3]. The ethanol extract was homogenized, filtered and stored at $-20{ }^{\circ} \mathrm{C}$ for further analysis. For determination of 
the contents of cysteine sulfoxides, water extraction of $5 \mathrm{~g}$ onion bulbs was carried out according to Mostafa et al. [2]. For determination of chlorophyll content, cold acetone extraction of $5 \mathrm{~g}$ onion leaves was carried out according to Yamauchi and Watada [26].

\subsubsection{Determination of carbohydrate content}

Twenty $\mu \mathrm{l}$ of filtered bulb ethanol extract were injected into Hitachi Elite-LaChrom HPLC coupled with Hitachi L-7490 refractive index (RI) detector and LiChroCART 250-4.0 NH 2 column. The mobile phase was $80 \%$ acetonitrile in the isocratic mode at a flow rate $0.8 \mathrm{ml} \mathrm{min}^{-1}$.

\subsubsection{Determination of flavonoid content}

The contents of flavonol compounds in the bulb extracts were measured by HPLC-DAD set at $360 \mathrm{~nm}$ according to Abdelrahman et al. [3].

\subsubsection{Organic acids}

For determination of citric acid and malic acid contents, one ml of filtered bulb ethanol extract was freeze-dried and dissolved in one $\mathrm{ml}$ millipore water. $100 \mu \mathrm{l}$ of sample were injected into HPLC-DAD, set at $210 \mathrm{~nm}$ coupled with LiChroCART RP-18 250-4.0 column. Samples eluted using isocratic system (water:methanol:50mM phosphoric acid, 69:1:30, v/v/v) with flow rate of $1 \mathrm{ml} \mathrm{min}^{-1}$.

\subsubsection{Free amino acids}

For determination of the contents of amino acids in the bulb extracts, the Waters Pico-Tag method and reagents were used. $100 \mu \mathrm{l}$ of sample were injected in Waters 600 HPLC coupled with Waters 486 tunable absorbance detector set at $254 \mathrm{~nm}$ and Waters Pico-tage amino acid

column set at $43^{\circ} \mathrm{C}$. Sample eluted with gradient system at constant flow rate $1 \mathrm{ml} \mathrm{min}{ }^{-1}$ (A: Pico-tage, B: 60\% acetonitrile).

\subsubsection{Determination of S-alk(en)yl-L-cysteine sulfoxides}

Contents of S-alk(en)yl-L-cysteine sulfoxides (ACSOs) were determined in the bulb extracts using HPLC-DAD set at $220 \mathrm{~nm}$, according to Mostafa et al., [2]. 


\subsubsection{Determination of total phenolic and total ascorbic acid contents}

Total phenolic contents in the leaf ethanol extracts were determined by the Folin-Ciocalteau method [27]. Total ascorbic acid content in the bulb tissue was extracted using $10 \%$ metaphosphoric acid and determined according to Roe and Oesterling [28].

\subsubsection{Determination of chlorophyll and carotenoid contents}

Chlorophyll and carotenoid contents in the leaf ethanol extracts were determined using HPLC UV/FL detector, according to Yamauchi and Watada [26].

\subsection{Determination of antioxidant activity}

The radical scavenging activities of antioxidant in the bulb extracts against 1,1-diphenyl-2picrilhydrazyl (DPPH) radical were determined as described by Abdelrahman et al., [3].

\subsection{Data analyses}

Experiments were conducted in completely randomized designs and results were presented as means \pm standard errors of three independent replicates. In chromatographic assays, each replicate solution was injected twice and averaged peaks were used for calculation. Difference between means was assessed by Tukey's multiple-comparison test and independent Student's ttest. All statistical analyses and graphical illustration were carried out by SPSS software version 20 and GraphPad Prism software version 6.05. Heatmap was constructed using open access R program version 3.2.0 (https://www.r-project.org/). Metabolite pathway was constructed using KEGG pathway database (http://www.genome.jp/kegg/pathway.html).

\section{Results}

In our previous studies, we were able to illustrate the potential roles of PGPFs isolated from rhizosphere soil in India, which may be applied to improve the crop production and reduce the disease incidence in sunflower and tomato plants, with a certain focus on the transcriptional regulation and enzymatic activity involved in the host plant $[9,16]$. This study extended the previous work to demonstrate that $T$. longibrachiatum isolated from desert soil in Egypt can confer beneficial agronomic traits to onion, as example of monocot plants, and induce disease resistance to FOC. The metabolite profiling approach was selected to explore the contribution of 
T. longibrachiatum isolate T1 to the accumulation of key metabolites, which subsequently leads to the improvement of onion growth and development, as well as its tolerance to oxidative stress.

\subsection{Isolation, biochemical and molecular characterization of the PGPFs}

In pursuit for a prospective PGPF isolates suited for the arid climatic zone, two Trichoderma isolates T1 was obtained from the extremely hot desert soil and T2 from freshwater of the Nile river at Aswan governorate, Egypt. The climatic conditions in this region ranged between very hot dry summer to moderately cold dry winter. The two Trichoderma isolates were selected based on their morphological and microscopic observation, as well as the positive colonization of onion roots. The selected isolates were further studied in-depth for their molecular identification using internal transcribed spacers (ITS) region prior to their biochemical screening for PGPF abilities. PCR amplification fragments of the ITS regions with the length between 530 and 600 bps were generated using specific primers. These fragments were sequenced separately, and the sequences were deposited in GenBank under accession numbers from KR233645 to KR233646. The blast search results showed high ITS sequence similarity of T1 (98\% sequence identity, Evalue 0.0$)$ and T2 (97\% sequence identity, E-value 0.0$)$ to that of T. longibrachiatum accession numbers KP671488.1 and KP316443.1, respectively, which were isolated from rhizosphere soil of a different biodiversity. T1 showed high thermal stability up to $45^{\circ} \mathrm{C}$, while $\mathrm{T} 2$ up to $35^{\circ} \mathrm{C}$. A significant reduction in the $\mathrm{pH}$ value of PVK broths inoculated with T1 (from pH 7.0 to $5.76 \pm$ 0.01 ) and T2 (from pH 7.0 to $5.79 \pm 0.01$ ) was observed after 21 days of incubation (Supplementary Table S1). T1 displayed the highest fungal growth inhibition percentage with $35.43 \pm 5.47 \%$ and $31.99 \pm 1.01 \%$ against Fusarium FOC-AF22 and FOC-TA, respectively, followed by $\mathrm{T} 2$ with $30.92 \pm 6.66$ and $27.17 \pm 2.75 \%$ against the respective strains (Supplementary Fig. S1). Furthermore, the two examined isolates exhibited a fair to strong ability toward phosphorus solubilization ranging from $87.14 \pm 2.02 \mu \mathrm{g} \mathrm{ml}^{-1}$ (T2) to $210.34 \pm$ $15.25 \mu \mathrm{g} \mathrm{ml}^{-1}$ (T1). Weak to strong abilities for IAA induction were recorded ranging from 2.53 $\pm 0.39 \mu \mathrm{g} \mathrm{ml}^{-1}$ (T2) to $28.33 \pm 5.33 \mu \mathrm{g} \mathrm{ml}^{-1}$ (T1) (Supplementary Table S1).

\subsection{Effects of T. longibrachiatum on onion seed germination and onion bulb growth parameters} A significant $(P<0.05)$ enhancement of early seedling emergence, germination percentage $(60 \mathrm{~h}$ after sowing) and seedling weight and height (one month-old seedling) was observed in T1- 
onion seeds treatment in comparison with T2-treatment and control (Fig. 1 and Supplementary Fig. S2). Under greenhouse conditions, T1-primed onion exhibited a remarkable increase in bulb weight, bulb size and plant height. However, bulb dry matter and moisture content were statistically not significant as compared with control (Table 1 and Supplementary Fig. S3)

\subsection{Effects of T1-treatment on the disease resistance of onion plants against FOC infection} As shown earlier in Supplementary Fig. S1, T1 exhibited strong capability to inhibit growth of FOC strain TA on a plate assay. As a means to determine whether T1-treatment could also effectively defend onion plants against FOC strain TA, we examined the effects of T1-priming on resistance of onion plants against FOC infection under greenhouse conditions. A significant $(P<0.001)$ reduction in Fusarium basal rot disease symptom was observed in T1-primed onion plants challenged with FOC (T1+FOC) as compared with SDW-treated onion plants challenged with FOC (FOC) (Fig. 2). The highest disease symptom of $88.33 \%$ was recorded in FOC; however, only $23.33 \%$ disease symptom was observed in T1+FOC. No disease symptom was detected in the negative SDW-treated control.

\subsection{Effects of T1- treatment on the metabolite profile of onion plants with and without FOC infection}

We hypothesized that up-regulation of primary and secondary metabolites occurs during T1onion-FOC interaction which leads to onion defense responses. To verify this hypothesis, the relative levels of 38 known metabolites were determined in all samples conditions (Control, T1 and T1+FOC), out of which 21 were significantly detected in T1 alone and 25 in T1+FOC. The metabolite data were subjected to volcano plot analysis (Fig. 3) and heatmap clustering (Fig. 4) to obtain a scatter view of the metabolites distribution within each treatment. The volcano plot revealed a clear separation of the significant metabolite accumulation with each treatment, demonstrating the high reproducibility of the different treatments as well as the significant and differential effects of the treatments on the metabolic levels.

Significant $(P<0.05)$ increase was detected in the aldopentose monosaccharides, including xylose and arabinose and non-structural soluble sugars, including fructose in T1- and T1+FOC-treated onion bulbs. However, sucrose level decreased, while oligosaccharides, including fructan and raffinose, accumulated in T1+FOC-treated onion bulbs only. Glucose 
content was statistically unchanged in T1- and T1+FOC-treated onion bulbs compared with control (Fig. 4, Supplementary Table S2 and Supplementary Fig. S4). Furthermore, the total sugar contents in T1- and T1+FOC-treated onion bulbs were similar with $93.85 \pm 7.08$ and 93.22 $\pm 6.35 \mathrm{mg} \mathrm{g}^{-1}$ fresh weight $(\mathrm{FW})$, respectively. Moreover, glucose:fructose (G:F) ratio was much higher in control ( $1.33 \pm 0.19)$ when compared with that in T1- and T1+FOC-treated onion bulbs (0.61 \pm 0.03 and $0.54 \pm 0.03$, respectively) (Fig. 3 and Supplementary Table S2).

The flavonol compounds, including quercetin 3-O-glucoside, quercetin 4'-O-glucoside, quercetin and kaempferol, were significantly $(P<0.05)$ higher in T1- and T1+FOC-treated onion bulbs, with 1.50- (quercetin 4'-O-glucoside), 2.42- (3-O-glucoside) and 6.66-fold (kaempferol) increase in comparison with control. However, quercetin 3, 4'-O diglucoside contents in T1-, T1+FOC-treated and control bulbs were statistically unchanged (Fig. 4 and Supplementary Table S2). The flavonoid profile of T1-, T1+FOC-treated and control bulbs showed a domination of two major flavonol compounds quercetin 3,4'-O-diglucoside and quercetin 4'-O-glucoside followed by quercetin (Supplementary Fig. S5).

T1- and T1+FOC-treated onion bulbs exhibited the highest significant $(P<0.05)$ accumulation of amino acids, ranged from 2.40- to 7.0-fold in T1- and 1.73- to 10.0-fold increase in T1+FOC-treated onion bulbs, with the exception of aspartic acid and glutamic acid whose content decreased compared with control (Fig. 4, Supplementary Table S2 and Supplementary Fig. S6). The organic acid content, including malic acid and citric acid, did not show any significant change in T1-treated onion bulbs. However, a significant decrease was observed in the T1+FOC-treated onion bulbs in comparison with control (Fig. 4, Supplementary Table S2 and Supplementary Fig. S6).

Our findings revealed substantially higher cysteine sulfoxides (ACSOs) contents in T1and T1+FOC-treated onion bulbs as compared with control (Fig. 4 and Supplementary Table S2). The ACSO distribution pattern in the T1- and T1+FOC-treated onion bulbs showed a spiking peak of methiin (MeCSO), isoalliin (PeCSO) and a trace amount of alliin (AlCSO) (Supplementary Fig. S7). Moreover, total ascorbic acid (vitamin C) showed a significant ( $P>$ 0.005) accumulation in the bulb tissues of the T1- and T1+FOC-treated onion $(0.18 \pm 1.25$ and $0.23 \pm 0.02 \mathrm{mg} \mathrm{g}^{-1} \mathrm{FW}$, respectively) compared with control $\left(0.10 \pm 0.97 \mathrm{mg} \mathrm{g}^{-1} \mathrm{FW}\right)$ (Fig. 3 and Supplementary Table S2). 
Analysis of chlorophyll content is essential for monitoring the fitness of the internal apparatus during photosynthetic process within plant leaves [29,30]. In the present study, T1and T1+FOC-treated onion leaves showed significant accumulation in the chlorophyll a, $\beta$ carotene, lutein and neoxanthin with 2.20-, 2.43-, 1.67- and 1.96-fold increase in T1- and 2.62-, 2.77-, 1.0- and 2.51-fold increase T1+FOC-treated leaves, respectively, relative to control (Fig. 4 and Supplementary Table S2).

\subsection{Metabolite circuit under T1- and T1+FOC-treatment}

Metabolome analysis provides a powerful means to gain novel insight into the metabolic network and how the metabolite response to environmental cues [18,31]. For this purpose, metabolic circuits obtained from T1- and T1+FOC-treated onion plants were constructed using the Kyoto Encyclopedia of Genes and Genomes (KEGG) database (Fig. 5). T1- and T1+FOCtrerated bulbs showed a strong up-regulation in phenylpropanoid pathway relative to SDWtreated control, starting from upstream level with phenylalanine to the downstream pool with flavonol biosynthesis. The second main triggered pathway under T1- and T1+FOC-treated bulbs was linked to carbohydrate metabolism through which the carbon flux was directed to biosynthesis of cell wall carbohydrates, monosaccharides and oligosaccharides. In addition, sulfur assimilation pathway was up-regulated in T1- and T1+FOC-treated bulbs which could be mainly attributed to the improvement in sulfur uptake. Thus, the role T. longbrichatium in sulfur assimilation and transport would be an interesting point of research.

\subsection{Antioxidants}

T1- and T1+FOC-treated onion bulb extracts revealed a significantly $(P<0.001)$ higher DPPH scavenging activity ( $\mathrm{IC}_{50}, 14.96 \pm 1.14$ and $13.36 \pm 0.33 \mathrm{mg}^{-1}$, respectively) in comparison with

control $\left(24.85 \pm 0.05 \mathrm{mg}^{-1}\right)$. Furthermore, the DPPH inhibition percentage recorded significantly higher values with $74.34 \pm 2.37$ and $78.60 \pm 1.42 \%$ in the T1- and T1+FOC-treated onion bulbs, respectively, relative to control $(66.25 \pm 1.34 \%)$.

\section{Discussion}

Little is known about the host mechanism that connects the Trichoderma root colonization to the metabolite dynamics, leading to activation of the plant developmental and stress responses. It's 
assumed that Trichoderma induces the activation of a signaling cascade that provokes a variety of responses, including accumulation of antimicrobial reactive oxygen species (ROS) and induction of defense-related secondary metabolites [32].

In the current study, the biochemical and molecular characterizations of two $T$. longibrachiatum isolates coupled with metabolites profiling of the pretreated-onion challenged with FOC, have allowed us to categorize the potential PGPF isolates and identify the metabolites involved in the onion growth and stress responsiveness induced by this beneficial fungus. The two T. longibrachiatum isolates T1 and T2 showed high thermal stability, root colonization ability and antagonistic nature against FOC, (Supplementary Table S1 and Supplementary Fig. S1), which potentiate the prospective applications of these isolates towards arid climatic conditions and inhibition of FOC growth through direct antagonism and mycoparasitism [21]. However, a significant variability in their PGPF traits was observed. T1 exhibited a significantly stronger P solubilization (Supplementary Table S1) and much higher IAA induction (Supplementary Table S1), as compared with T2, suggesting that T1 might likely act through auxin-dependent mechanism as plant growth stimulator as reported for several PGPFs isolated earlier [9, 32,33]. In agreement with this finding, T1-treatment enhanced germination of onion seeds, seedling weight and height when compared with T2-treatment and SDW-treated control (Fig. 1). Similar observations of early seed germination were reported in onion [34], cucumber [17] and tomato [9], in seed-treatments with various Trichoderma isolates.

Thus, our data have made a clear discrimination between the two PGPF T1 and T2 isolates, giving more weight to T1-treatment as a selective PGPF for onion crop improvement. To provide further evidence on the potential of T1 in enhancement of onion productivity, T1 was subjected to a greenhouse trail. A remarkable increase was detected in the bulb weight and size, as well as plant height in six month-old T1-primed onion (Table 1 and Supplementary Fig. S3) in comparison with unprimed control. The increases in plant growth and biomass have been reported in a number of Trichoderma-host systems, such as sugar cane, chili and tomato $[9,15,35]$. Several possible mechanisms have been suggested to explain this beneficial response of Trichoderma on the plant growth, which include control of deleterious root microorganisms, direct production of growth simulating factors, such as plant hormones, and increase nutrient uptake through enhanced root growth [9,36]. Furthermore, T1-priming induced resistance of onion plants against FOC infection under greenhouse conditions (Fig. 2). Species of 
Trichoderma have been found to be effective in controlling the level of diseases caused by $F$. oxysporum in may crop plants $[37,38]$. However, the levels of disease control caused by $F$. oxysporum were found to be variable within different strains of Trichoderma [38,39].

The accumulation pattern of the carbohydrates in T1- and T1+FOC-treated onion bulbs showed significant increase in xylose, arabinose, fructose, fructan and raffinose when compared with control (Fig. 4, Supplementary Fig. S4 and Supplementary Table S2). The high level of sugars in plant tissues enhances plant resistance against pathogens, acting as ROS scavengers, cell wall reinforcements, osmo-protectants and signaling molecules [40,41]. The accumulation of arabinose and xylose as major components of hemicellulose polymers and hydroxyproline hyperrich glycoproteins in T1- and T1+FOC-treated onion bulbs is believed to play a structural role in strengthening cell wall against different biotic or abiotic stresses [42,43]. The increase in level of fructose monosaccharides, and fructan and raffinose oligosaccharides in bulbs treated with T1and T1+FOC may suggest their involvement in antioxidant and immune stimulatory mechanisms in onion that lead to disease prevention [44-46]. Our finding is in agreement with recent reports in Trichoderma-plant-pathogen interactions which revealed an increase in arabinose, xylose and carbohydrate metabolism $[47,48]$. Our data and these recent reports have enabled us to conclude that the activation of onion defense against FOC and improvement of growth parameters by $T$. longibrachiatum require an increase in the energy supply that should come from reprograming in the carbohydrate metabolism [13,49]. From a customer market consideration, the high fructose content in the T1-primed onion will positively enhance the onion sweetness which is preferred by consumers as a fresh vegetable [50].

Metabolomics analyses with different plant resources showed that flavonoids form a key stone in defending plants against adverse conditions by reducing the accumulation of ROS triggered by biotic or abiotic stress [7,51-53]. A recent report by Lee et al., [55] has shown an increase in the flavonoid level after Fusarium pathogen inoculation of onion bulbs, providing an important highlight towards the functional role of the flavonoids in the onion defense against FOC. In the present study, T1- and T1+FOC-treated onion plants stimulated the accumulation of quercetin 3-O glucoside, quercetin $4^{\prime}$-O-glucoside, quercetin and kaempferol (Fig. 4, Supplementary Fig. S5 and Supplementary Table S2), supplying a further evidence of $T$. longibrachiatum role in onion defense mechanism trough the up-regulation of flavonoid biosynthesis. In support of our finding, recent reports revealed an increase in flavonolignan 
content in milk thistle (Silybum marianum) plant pretreated with different Trichoderma strains [56], and total flavonoid content in rice pretreated with T. asperellum [57]. The flavonoid accumulation in T1- and T1+FOC-primed onion bulbs might be attributed to activation of phenylalanine ammonia lyase (Pal) signaling cascade by Trichoderma as reported earlier $[9,48]$. We hypothesize that T1- and T1+FOC-treatments induce the accumulation of flavonoids in onion bulbs, especially quercetin and kaempferol, as well as total phenolics as potent antioxidants to overcome the oxidative damage generated by FOC and to restrict the penetration of T. longibrachiatum and FOC into the intracellular spaces at cortex and vascular bundles $[7,57]$. Furthermore, the dramatic increase in the quercetin and slight decrease in quercetin glycosides after pathogen inoculation might be attributed to the hydrolysis of glyosidic bond in the quercetin glycosides by hydrolysis enzymes that are released by FOC $[55,58]$. From a nutritional point of view, flavonoids have antioxidant powers that may provide important health benefits, immune enhancements and other pharmaceutical properties [59,60].

Arginine was the most highly accumulated amino acid detected in T1- and T1+FOCprimed onion bulbs when compared with control (Fig. 4, Supplementary Fig. S6 and Supplementary Table S2), which is the main precursor for the biosynthesis of free polyamines that are known to play a critical roles in various biological processes, including plant responses to biotic and abiotic stresses [61]. A clear increase in aromatic amino acids, including phenylalanine, was also noted in T1- and T1+FOC-treated onion bulbs (Fig. 4, Supplementary Fig. S6 and Supplementary Table S2). Phenylalanine is the building block for phenylpropanoid pathway, one of the most important pathways involved in the plant stress responses [62]. Furthermore, tryptophan and methionine levels increased in onion bulbs under T1+FOCtreatment (Fig. 4, Supplementary Fig. S6 and Supplementary Table S2). Tryptophan pathway has been shown to be involved in the establishment of effective physical defense responses via the production of serotonin and indolic glucosinolates [63,64]. Methionine is a well-known inducer of plant defense responses and important precursor for ethylene and polyamine biosynthesis via S-adenosyl methionine [61,65]. Proline, which is an important metabolite for both abiotic and biotic stress responses in plants due to its function in reducing oxidation [66,67], was significantly higher in the T1- and T1+FOC-treatment bulbs (Fig. 4, Supplementary Fig. S6 and Supplementary Table S2). In general, a positive relationship between amino acid accumulations 
and Trichoderma treatment has been reported in several plant species, such as Arabidposis [48] and Theobroma cacaco [68].

In addition, T. longibrachiatum expressed high levels of MeCSO and PeCSO (Fig. 4, Supplementary Fig. S7 and Supplementary Table S2), which correlated with a strong sulfur smell and a hot pungent taste that could provide an important insight to onion quality for taste and aroma development. ACSOs are physiologically active and widely used as antibiotic and antitumor agents [69]. The antibacterial and antifungal properties of ACSOs are important for onion during extreme environmental conditions [70]. The high ACSO content noted in T1- and T1+FOC-treated onion bulbs can be explained by the positive effects of $T$. longibrachiatum on water and mineral uptakes [12,13]. In support of this hypothesis, an earlier report showed that the increase in ACSO level was positively correlated with mineral uptake, particularly with that of sulfur [71]. In addition, an improvement of the plant sulfur nutritional status under sulfur starvation in Lotus japonicus colonized by arbuscular mycorrhizas was reported [72].The detailed mechanism of Trichoderma spp. on the sulfur assimilation pathway will be an interesting point of research.

Carotenoids and chlorophylls are functionally important to protect the plant system against photooxidative stress by quenching excited molecules [30,73]. The detected peaks of carotenoids and chlorophylls in T1- and T1+FOC-treated onion leaves in comparison with control were in line with previous reports that found higher levels of chlorophyll in cucumber [36], Arabidopsis [74], and Sorghum-sudangrass (Sorghum $\times$ drummondi) [75] pretreated with Trichoderma. It might be possible that the physical contact between Trichoderma and onion plants resulted in an increase in the level of auxin or other hormones that might act to contribute to enhancement of chlorophyll content and to growth-promoting status [9,36,75].

In addition, the results of the DPPH assay conducted in this study clearly advocate the effects of T1 on the onion antioxidant machinery. Plants have evolved two different biological processes to cope with free radicals by enzymatic and non-enzymatic processes; the later includes the accumulation of ascorbic acid, flavonoids, amino acids, sugars and carotenoids [7]. Our metabolites profiling (Fig. 3 and Supplementary Table S2) revealed a substantial accumulation in these metabolites in the T1- and T1+FOC-primed onion plants compared with control, which provides a building stone to the functional role of the Trichoderma-primed onion against ROS accumulation generated by abiotic or biotic stress. Our finding was in harmony with 
the work of Brotman et al., [32], which reported the activation of antioxidant systems in Trichoderma-Arabidopsis.

In conclusion, our results demonstrated that the application of T. longibrachiatum T1 in onion seed priming was effective in the plant growth improvement, as well as in induction of defense mechanisms, leading to enhanced resistance of onion plants against FOC. The detailed analysis of the broad-scale metabolites revealed an increase in a certain classes of metabolites, which may explain the positive effects of T1 in the plant growth promotion and improvement of onion resistance against FOC. Figure 6 summarized the model of T1-onion-FOC interactions and associated mechanisms, which may provide an insight into the prospective roles of $T$. longibrachiatum in onion development and its tolerance to oxidative stress.

\section{Acknowledgments}

This work was supported by the Strategic International Research Cooperative Program, the Japan Science and Technology Agency (JST), and Egyptian mission and culture bureau. The authors declare no conflict of interest.

\section{References}

[1] FAOSTAT. The online database published by FAO-Food and Agriculture Organization of the United Nations, (2013) (http://faostat3.fao.org/download/Q/QC/E).

[2] A. Mostafa, J. Sudisha, M. El-Sayed, S. Ito, T. Ikeda, N. Yamauchi, M. Shigyo, Aginoside saponin, a potent antifungal compound, and secondary metabolite analyses from Allium nigrum L., Phytochem. Lett. 6 (2013) 274-280.

[3] M. Abdelrahman, S. Hirata, S. Ito, N. Yamauchi, M. Shigyo, Compartmentation and localization of bioactive metabolites in different organs of Allium roylei. Biosci. Biotechnol. Biochem. 7 (2014) 1112-1122.

[4] G. Caruso, S. Conti, G. Villari, C. Borrelli, G. Melchionna, M. Mintutolo, G. Russo, C. Amalfitano, Effects of transplanting time and plant density on yield, quality and antioxidant content of onion (Allium cepa L.) in southern Italy, Sci. Hortic. 166 (2014) 111-120. 
[5] J. Enciso, J. Jifon, J. Anciso, L. Ribera, Productivity of Onions Using Subsurface Drip Irrigation versus Furrow Irrigation Systems with an Internet Based Irrigation Scheduling Program, Inter. J. Agron. (2015) 178180.

[6] E.J. Lee, J.K. Suh, Analytical methods of pyruvic acid and difference of pyruvic acid content in relation to bulb characteristics in onion, J. Hortic. Sci. Technol. 27 (2009) 337-342.

[7] R. Nakabayashi, K. Saito, Integrated metabolomics for abiotic stress responses in plants. Curr. Opin. Plant Biol. 24 (2015) 10-16.

[8] D.J. Studholme, B. Harris, K. LeCocq, R. Winsbury, V. Perera, L. Ryder, J.L. Ward, M.H. Beale, C.R. Thornton, M. Grant, Investigating the beneficial traits of Trichoderma hamatum GD12 for sustainable agriculture-insights from genomics, Front. Plant Sci. 4 (2013) 258.

[9] J. Sudisha, M. Abdelrahman, L.S.P. Tran, S. Ito, Characterization of rhizosphere fungi that mediate resistance in tomato against bacterial wilt disease. J. Exp. Bot. 64 (2013) 3829-3842.

[10] L. Chen, I.C. Dodd, J.C. Theobald, A.A. Belimov, W.J. Davies, The rhizobacterium Variovorax paradoxus 5C-2, containing ACC deaminase, promotes growth and development of Arabidopsis thaliana via an ethylene-dependent pathway, J. Exp. Bot. 64 (2013) 1565-1573.

[11] N.B. Anupama, J. Sudisha, S. Ito, K.N. Amruthesh, P.L.S. Tran, Improvement of growth, fruit weight and early blight disease protection of tomato plants by rhizoshpere bacteria is correlated with their beneficial traits and induced biosynthesis of antioxidant peroxidase and polyphenol oxidase, Plant Sci. 231 (2015) 62-73.

[12] S.C.M. Van Wees, S. Van der Ent, C.M.J. Pieterse, Plant immune responses triggered by beneficial microbes, Curr. Opin. Plant Biol. 11 (2008) 443-448.

[13] M. Shoresh, G.E. Harman, F. Mastouri, Induced systemic resistance and plant responses to fungal biocontrol agents, Ann. Rev. Phytopathol. 48 (2010) 21-43.

[14] G.E. Harman, C.R. Howell, A. Viterbo, I. Chet, M. Lorito, Trichoderma speciesopportunistic a virulent plant symbionts, Nat. Rev. Microbiol. 2 (2004) 43-56. 
[15] M.S. Islam, M.A. Rahman, S.H. Bulbul, M.F. Alam, Effect of Trichoderma on seed germination and seedling parameters in chilli, Int. J. Exp. Agric. 2 (2011) 21-26.

[16] A. Nagaraju, J. Sudisha, S. Mahadevamurthy, S. Ito, Seed priming with Trichoderma harzianum isolates enhances plant growth and induces resistance against Plasmopara halstedii, an incitant of sunflower downy mildew disease, Australia J. Plant Pathol. 41 (2012) 609-620.

[17] S. Islam, A.M. Akandaa, F. Sultanab, M. Hossaina, Chilli rhizosphere fungus Aspergillus spp. PPA1 promotes vegetative growth of cucumber (Cucumis sativus) plants upon root colonization, Arch. Phytopathol. Plant Protec. 47 (2013) 1231-1238.

[18] T.F. Jorge, J.A. Rodrigues, C. Caldana, R. Schmidt, J.T. van Dongen, J. Thomas-Oates, C. AntoÂnio, Mass spectrometry-based plant Metabolomics: Metabolite responses to abiotic stress. Mass Spectrometry Rev. (2015) DOI 10.1002/mas.21449.

[19] G. Segarra, S. Van der Ent, I. Trillas, C.M.J. Pieterse, MYB72, a node of convergence in induced systemic resistance triggered by a fungal and a bacterial beneficial microbe. Plant Biol. 11 (2009) 90-96.

[20] A.M Amal., A.A. Amina, Alterations of some secondary metabolites and enzymes activity by using exogenous antioxidant compound in onion plants grown under sea water stress, American-Euroasian J. Sci. Res. 3 (2008) 139-146.

[21] A. Coşkuntuna, N. Özer, Biological control of onion basal rot disease using Trichoderma harzianum and induction of antifungal compounds in onion set following seed treatment, Crop Protec. 27 (2008) 330-336.

[22] S.A. Rosenthal, D. Furnari, The use of a cycloheximide-chloramphenicol medium in routine culture for fungi, J. Investigative Dermatol. 28 (1957) 367-371.

[23] M.B. Shivanna, M.S. Meera, M. Hyakumachi, Role of the root colonization ability of plant growth promoting fungi in the suppression of take-all and common root rot of wheat, Crop Protec. 15 (1996) 497-504.

[24] F.S. Watanabe, S.R. Olsen, Test of an ascorbic acid method for determining phosphorus in water and $\mathrm{NaHCO}_{3}$ extracts from soil, Soil Sci. Soc. Amer. J. 29 (1965) 677-678. 
[25] S.A. Gordon, R.P. Weber, Colorimetric estimation of indole acetic acid, Plant Physiol. 26 (1951) 192-195.

[26] N. Yamauchi, A.E. Watada, Regulated Chlorophyll Degradation in Spinach Leaves during Storage, J. Amer. Soc. Hortic. Sci. 116 (1991) 58-62.

[27] O. Folin, W. Denis, A colorimetric method for the determination of phenols and phenol derivatives in urine, J. Biol Chem 22 (1915) 305-308.

[28] H.J. Roe, M.J. Oesterling, The determination of dehydroascorbic acid and ascorbic acid in plant tissues by the 2, 4-Dinitrophenylhydrazine method, J. Biol. Chem. 153 (1943) 511-517.

[29] A.J. Clark, W. Landolt, J.B. Bucher, R.J. Strasser, Beech (Fagus sylvatica) response to ozone exposure assessed with a chlorophyll fluorescence performance index, Environ. Pollut. 109 (2000) 501-507.

[30] M.A. Gururani, J. Venkatesh, P.L.S. Tran, Regulation of Photosynthesis during Abiotic Stress-Induced Photoinhibition, Mol. Plant, 8 (2015) 1304-1320.

[31] A.J. Lloyd, J.W. Allwood, C.L. Winder, W.B. Dunn, J.K. Heald, S.M. Cristescu, A. Sivakumaran, F.J.M. Harren, J. Mulema, K. Denby, R. Goodacre, A.R. Smith, L.A.J. Mur, Metabolomic approaches reveal that cell wall modifications play a major role in ethylenemediated resistance against Botrytis cinerea. Plant J. 67 (2011) 582-868.

[32] Y. Brotman, U. Landau, A. Cuadros-Inostroza, T. Takayuki, A.R. Fernie, I. Chet, A. Viterbo, L. Willmitzer, Trichoderma-Plant Root Colonization: Escaping Early Plant Defense Responses and Activation of the Antioxidant Machinery for Saline Stress Tolerance, PLoS Pathogens, 9 (2013) e1003221. doi:10.1371/journal.ppat.1003221.

[33] H.A. Contreras-Cornejo, L. Macias-Rodriguez, C. Cortes-Penagos, J. Lopez-Bucio, Trichoderma virens, a plant beneficial fungus, enhances biomass production and promotes lateral root growth through an auxin-dependent mechanism in Arabidopsis, Plant Physiol. 149 (2009) 1579-1592.

[34] A.J. Bennett, M.A. Andrew, J.M. Whipps, Performance of carrot and onion seed primed with beneficial microorganisms in glasshouse and field trials, Biol. Control.51 (2009) 417-426. 
[35] V. Singh, P.N. Singh, R.L. Yadav, S.K. Awasthi, B.B. Joshi, R.K. Singh, R.J. Lal, S.K. Duttamajumder, Increasing the efficacy of Trichoderma harzianum for nutrient uptake and control of red rot in sugarcane, J. Hortic. Forestry. 2 (2010) 66-71.

[36] L. Chaur-Tsuen, L. Chien-Yih, Screening strains of Trichoderma spp. for plant growth enhancement in Taiwan, Plant Pathol Bullet.11 (2002) 215-220.

[37] M. Verma, K.B. Satinder, R.D. Tyagi, R.Y. Surampalli, J.R. Valèro, Antagonistic fungi, Trichoderma spp.: panoply of biological control, Biochem. Engineering. J. 37 (2007) 1-20.

[38] M. Marzano, A. Gallo, C. Altomare, Improvement of biocontrol efficacy of Trichoderma harzianum vs. Fusarium oxysporum f. sp. lycopersici through UV-induced tolerance to fusaric acid. Biol. Control 67 (2013) 397-408.

[39] B. Nel, C. Steinberg, N. Labuschagne, A. Viljoen, The potential of nonpathogenic Fusarium oxysporum and other biological control organisms for suppressing Fusarium wilt of banana. Plant Pathol. 55 (2006) 217-223.

[40] D. Peshev, R. Vergauwen, A. Moglia, E. Hideg, W. Van den Ende, Towards understanding vacuolar antioxidant mechanisms: a role for fructans? J. of Exp. Bot. 64 (2013) 1025-1038.

[41] E. Keunen, D. Peshev, J. Vangronsveld, W. Van den Ende, A. Cuypers, Plant sugars are crucial players in the oxidative challenge during abiotic stress: extending the traditional concept, Plant Cell Environ. 36 (2013) 1242-1255.

[42] J.A. Dauwe, S.N. Holliday, S.D. Aitken, Mansfield metabolic dynamics during autumn cold acclimation within and among populations of Sitka spruce (Picea sitchensis), New Phytol. 194 (2012) 192-205.

[43] R.B. de Lima, B.T. dos Santosb, L.G. Esteves Vieirab, M.L. Lúcio Ferraresec, O. FerrareseFilhoc, L. Donattid, M.R. Torres Boegere, C.L.O. Petkowicz, Salt stress alters the cell wall polysaccharides and anatomy of coffee (Coffea arabica L.) leaf cells. Carbohydrate Polymers 112 (2014) 686-694. 
[44] J.D. Williamson, D.B. Jennings, W.W. Guo, D.M. Pharr, Sugars alcohols, salt stress and fungal resistance: polyols multifunctional plant protection. J. Amer. Soc. Hortic. Sci. 127 (2002) 467-473.

[45] D. Parker, M. Beckmann, H. Zubair, D.P. Enot, Z.C. Rios, D.P. Overy, S. Snowdon, N.J. Talbot, J. Draper, Metabolomic analysis reveals a common pattern of metabolic reprograming during invasion of three host plant species by Magnoporthegrisea. Plant J. 59 (2009) 723-737.

[46] W. Van den Ende, Multifunctional fructans and raffinose family oligosaccharides, Front. Plant Sci. 4 (2013) 247.

[47] M. Shoresh, G.E. Harman, The molecular basis of maize responses to Trichoderma harzianum T22 inoculation: a proteomic approach. Plant Physiol 147 (2008) 2147-2163.

[48] Y. Brotman, J. Lisec, M. Me'ret, I. Chet, L. Willmitzer, A. Viterbo, Transcript and metabolite analysis of the Trichoderma-induces systemic resistance response to Pseudomonas syringae in Arabidopsis thaliana, Microbiol 158 (2012) 139-146.

[49] M.D. Bolton, Primary metabolism and plant defense-fuel for the fire, Mol. Plant-Microbe Interact. 5 (2009) 487-497.

[50] S. Raines, C. Henson, M.J. Havey, Genetic analyses of soluble carbohydrate concentrations in onion bulbs, J. Amer. Soc. Hortic. Sci. 134 (2009) 618-623.

[51] T.A. Akhtar, H.A. Lees, M.A. Lampi, D. Enstone, R.A. Brain, B.M. Greenberg Photosynthetic redox imbalance influences flavonoid biosynthesis in Lemna gibba, Plant Cell Environ. 33 (2010) 1205-1219.

[52] C. Stushnoff, L.J.M. Ducreux, R.D. Hancock, P.E. Hedley, D.J. Holm, G.J. McDougall, J.W. McNicol, J. Morris, W.L. Morris, J.A. Sungurtas, S.R. Verrall, T. Zuber, M.A. Taylor, Flavonoid profiling and transcriptome analysis reveals new gene-metabolite correlations in tubers of Solanum tuberosum L. J. Exp. Bot. 61 (2010) 1225-1238.

[53] I. Ignat, I. Volf, VI. Popa, A critical review of methods for characterization of polyphenolic compounds in fruits and vegetables. Food Chem 126 (2011) 1821-1835. 
[54] K. Das, A. Roychoudhury, Reactive oxygen species (ROS) and response of antioxidants as ROS-scavengers during environmental stress in plants. Front Environ. Sci. 2 (2014) 53. doi: 10.3389/fenvs.2014.00053

[55] E.H. Lee, S.J. Lee, S. Park, S.W. Jeong, et al., Determination of flavonoid level variation in onion (Allium cepa L.) infected by Fusarium oxysporum using liquid chromatography-tandem mass spectrometry, Food Chem 133 (2012) 1653-1657.

[56] T. Hasanlooa, M. Kowsarib, S.M. Naraghia, O. Bagherib, Study of different Trichoderma strains on growth characteristics and silymarin accumulation of milk thistle plant, J. Plant Interact. 5 (2010) 45-49.

[57] M.C. Ferreira Rêgo, F. Ilkiu-Borges, M.C. Corsi de Filippi, L.A. Gonçalves, G. Barata da Silva, Morphoanatomical and biochemical changes in the roots of rice plants induced by plant growth-promoting microorganisms, J. Botany. (2014) 818797. doi:10.1155/2014/818797

[58] H.G. Kim, G.S. Kim, J.H. Lee, S. Park, W.Y. Jeong, Y.H. Kim, et al., Determination of the change of flavonoid components as the defense materials of Citrus unshiu Marc. Fruit peel against Penicillium digitatum by liquid chromatography coupled with tandem mass spectrometry, Food Chem. 128 (2011) 49-54.

[59] Singh B.N., B.R. Singh, R.L. Singh, Polyphenolics from various extracts/fractions of red onion (Allium cepa) peel with potent anti-oxidant and antimutagenic activities, Food Chemical Toxicol. 47 (2009a) 1161-67.

[60] N. Beesk, H. Perner, D. Schwarz, E. George, L.W. Kroh, S. Rohn, Distribution of quercetin-3, 4'-O-diglucoside, quercetin-4'-O-monoglucoside, and quercetin in different parts of the onion bulb (Allium cepa L.) influenced by genotype, Food Chem. 122 (2010) 566-571.

[61] D. Walters, Resistance to plant pathogens: possible roles for free polyamines and polyamine catabolism, New Phytol 159 (2003) 1469-8137.

[62] S. La Camera, G. Gouzerh, S. Dhondt, L. Hoffmann, B. Fritig, M. Legrand, T. Heitz Metabolic reprogramming in plant innate immunity: the contributions of phenylpropanoid and oxylipin pathways, Immunol. Rev 198 (2004) 267-284. 
[63] A. Ishihara, Y. Hashimoto, C. Tanaka, J.G. Dubouzet, T. Nakao, F. Matsuda, T. Nishioka, H. Miyagawa, K. Wakasa, The tryptophan pathway is involved in the defense responses of rice against pathogenic infection via serotonine production, Plant J. 54 (2008) 481-495.

[64] C. Consonni, P. Bednarek, M. Humphry, F. Francocci, S. Ferrari, A. Harzen, E. Loren van Themaat, R. Panstruga, Tryptophan-derived metabolites are required for antifungal defense in the Arabidopsis mlo2 mutant, Plant Physiol. 152 (2010) 1544-1561.

[65] B. Winterberg, L. ADu Fall, X. Song, D. Pascovici, N. Care, M. Molloy, S. Ohms, P.S. Solomon, The necrotrophic effector protein SnTox3 re-programs metabolism and elicits a strong defence response in susceptible wheat leaves, BMC Plant Biol. 14 (2014) 215.

[66] L. Szabados, A. Savour'e, Proline: a multifunctional amino acid, Trends in Plant Sci. 15 (2010) 89-97.

[67] X. Liang, L. Zhang, S.K. Natarajan, D.F. Becker, Proline Mechanisms of Stress Survival, Antioxid. Redox Signal. 19 (2013) 998-1011.

[68] H. Bae, R.C. Sicher, M.S. Kim, S.H. Kim, M.D. Strem, R.L. Melnick, B.A. Bailey, The beneficial endophyte Trichoderma hamatum isolate DIS 219b promotes growth and delays the onset of the drought response in Theobroma cacao, J. Exp. Bot. 60 (2009) 3279-3295.

[69] J. Kusterer, M. Keusgen, Cysteine sulfoxides and volatile sulfur compounds from Allium tripedale, J. Agric Food Chem. 58 (2010) 1129-1137.

[70] R.M. Fritsch, M. Keusgen, Occurrence and taxonomic significance of cysteine sulphoxides in the genus Allium (Alliaceae), Phytochem. 67 (2006) 1127--1136.

[71] J. McCallum, L. Thomas, M. Shaw, M. Pither-Joyce, S. Leung, M. Cumming, M.T. McManus, Genotypic variation in the sulfur assimilation and metabolism of onion (Allium cepa L.) I. Plant composition and transcript accumulation, Phytochem. 72 (2011) 882-887.

[72] M. Giovannetti, M. Tolosano, V. Volpe, S. Kopriva, P. Bonfante, Identification and functional characterization of a sulfate transporter induced by both sulfur starvation and mycorrhiza formation in Lotus japonicas, New Phytol. 204 (2014) 609-619. 
[73] Q. Bian, S. Gao, J. Zhou, J. Qin, A. Taylor, E. Johnson, F. Shang, Lutein and zeaxanthin supplementation reduces photooxidative damage and modulates the expression of inflammationrelated genes in retinal pigment epithelial cells, Free Radiol Biol Medicine 53 (2012) 1298-1307. [74] R. Hung, S. Lee, J.W. Bennett, Arabidposis thaliana as a model system for testing the effect of Trichoderma volatile organic compounds, Fungal Ecol. 6 (2013) 19-26.

[75] A.G. Babu, J. Shim, P.J. Shea, O.H. Byung-Taek, Penicillium aculeatum PDR-4 and Trichoderma sp. PDR-16 promote phytoremediation of mine tailing soil and bioenergy production with sorghum-sudangrass, Ecol. Engineering 69 (2014) 186-191. 


\section{Figure legends}

Fig. 1. Seed-priming effects of Trichoderma longibrachiatum isolates T1 and T2 on germination percentage of onion seeds (A), onion seedling height (B) and onion seedling weight (C). Seed germination values are means of three independent replications ( $n=3 ; 20$ seeds/replicate). Seedling height and weight values are means of eight independent replications ( $n=8)$. Bars represent standard errors. Different letters indicate statistically significant differences according to Tukey’s test $(P<0.05)$. FW, fresh weight.

Fig. 2. Effects of Trichoderma longibrachaitum T1-treatment on the reduction of Fusarium basal rot disease severity caused by Fusarium oxysporum f. sp. cepa (FOC) strain TA (A). Disease severity percentage in T1-primed onion plants challenged with FOC TA strain (T1+FOC), SDWtreated onion plants challenged with FOC (FOC), and sterile distilled water-treated-onion plants (Control) (B). Disease severity percentage was based on scale of 0-100 where $0=$ healthy and $100=$ extreme symptom. Values are means of three independent replications $(n=3)$. Bars represent standard errors. Significance level between Control versus T1+FOC and Control versus FOC is given as: * $(P<0.05),{ }^{* *}(P<0.01)$ and $* * *(P<0.001)$ according to an independent Student's t-test. ND, not detected.

Fig. 3. The volcano plot analyses of the metabolite fold changes in Trichoderma longibrachiatum T1-primed onion (A) and T1-primed onion plants challenged with Fusarium oxysporum f. sp. cepa TA strain (T1+FOC) (B) relative to sterile distilled water-treated control (Control). The base 2 logarithm of the fold changes of the metabolites is shown on the x-axis. The negative base 10 logarithm of the $p$-value of the metabolites is shown on the y-axis. A horizontal bar indicates the threshold of the significant level at 0.05. Each spot represents a single metabolite, and the metabolites with significant variability were colored. Total sugar content and glucose:fructose ratio were represented along with the examined metabolites. 
Fig. 4. Hierarchical clustering representation of the row-wise normalized level of the mean values of 38 metabolites detected in Trichoderma longibrachiatum T1-treated onion plants, T1primed onion plants challenged with Fusarium oxysporum f. sp. cepa TA strain (T1+FOC) and sterile distilled water-treated control (Control). Total sugar content and glucose:fructose ratio were represented along with the examined metabolites.

Fig. 5. Visualization of the metabolite changes and related pathways in Trichoderma longibrachiatum T1-treated onion plants (T1) and T1-primed onion plants challenged with Fusarium oxysporum f. sp. сера TA strain (T1+FOC), and sterile distilled water-treated control (Control). Red and yellow colors indicate up-regulation ( $\geq 2$ fold-change) and down-regulation ( $\leq 0.5$ fold-change), respectively, of metabolites relative to SDW-treated control. Bars show the absolute contents ( $\mathrm{mg} \mathrm{g}^{-1} \mathrm{FW}$ ) of each metabolite in each treatment (Control, $\mathrm{T} 1$ or $\mathrm{T} 1+\mathrm{FOC}$ ). FW, fresh weight.

Fig. 6. Schematic model of Trichoderma longibrachiatum isolate T1-onion-Fusarium oxysporum f. sp. серa interactions and associated mechanisms. 
Table 1. Effects of Trichoderma longibrachiatum T1-treatment on the height, bulb weight, size, dry matter and moisture content of the six-month-old onion plants grown under greenhouse conditions.

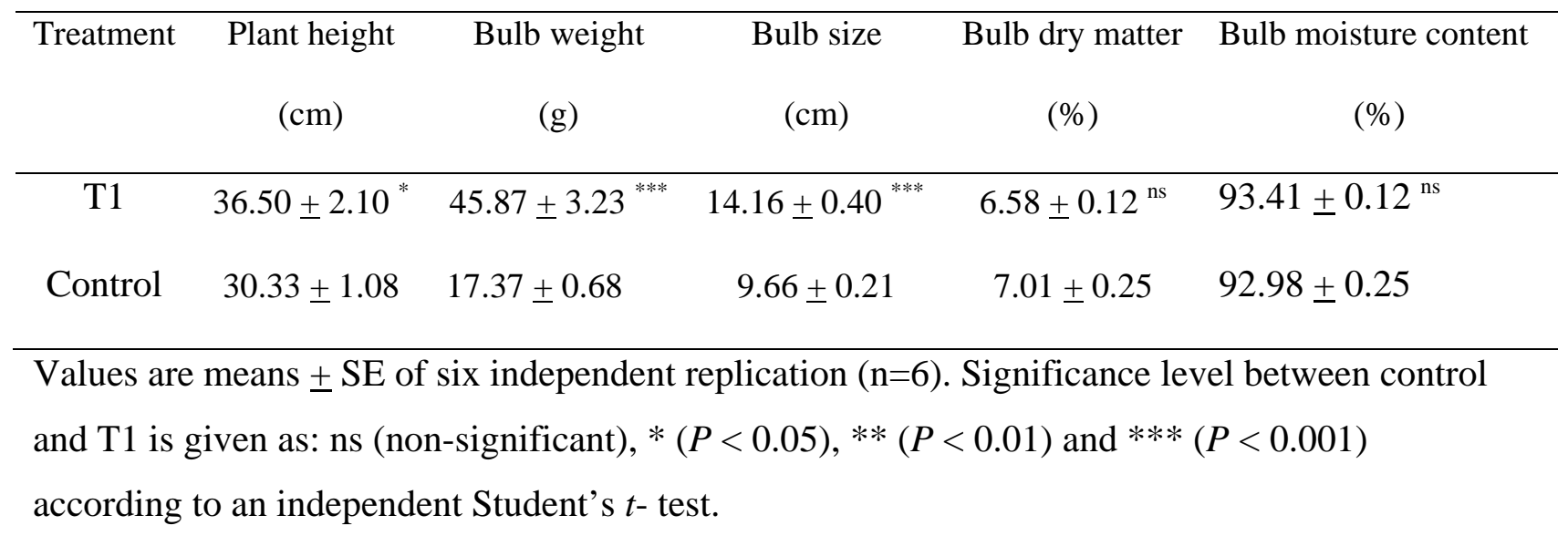



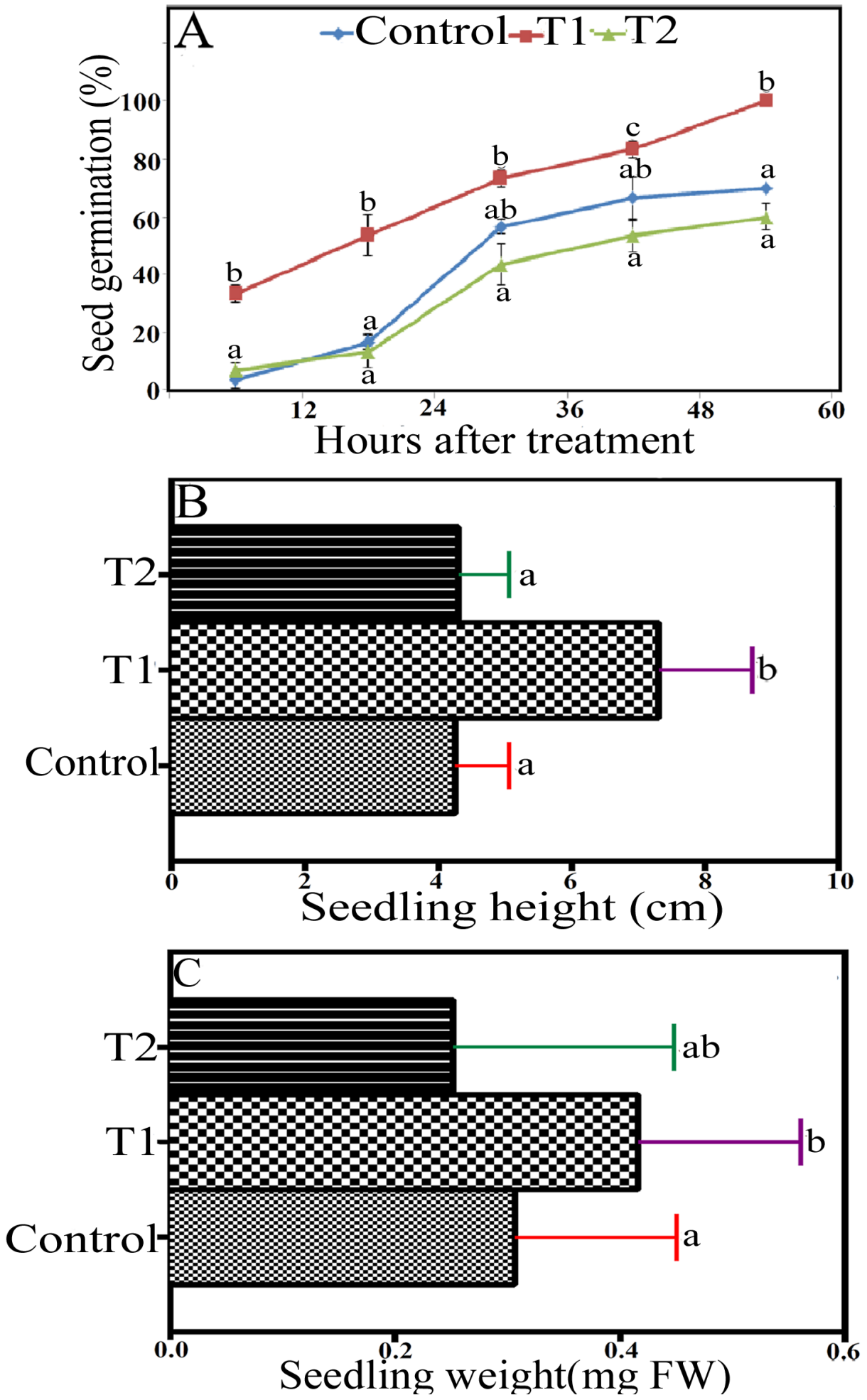

Figure 1 


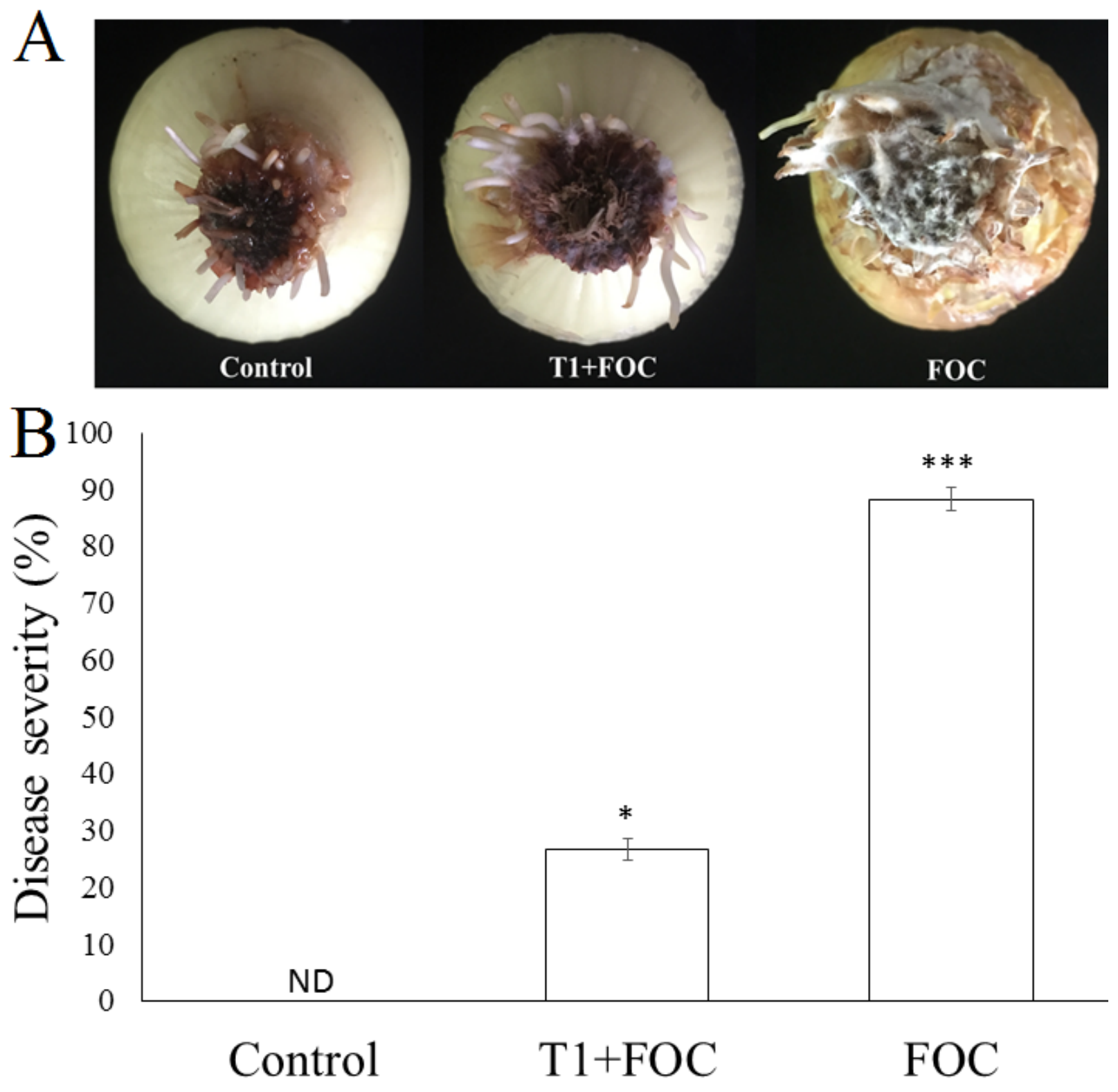

Figure 2 

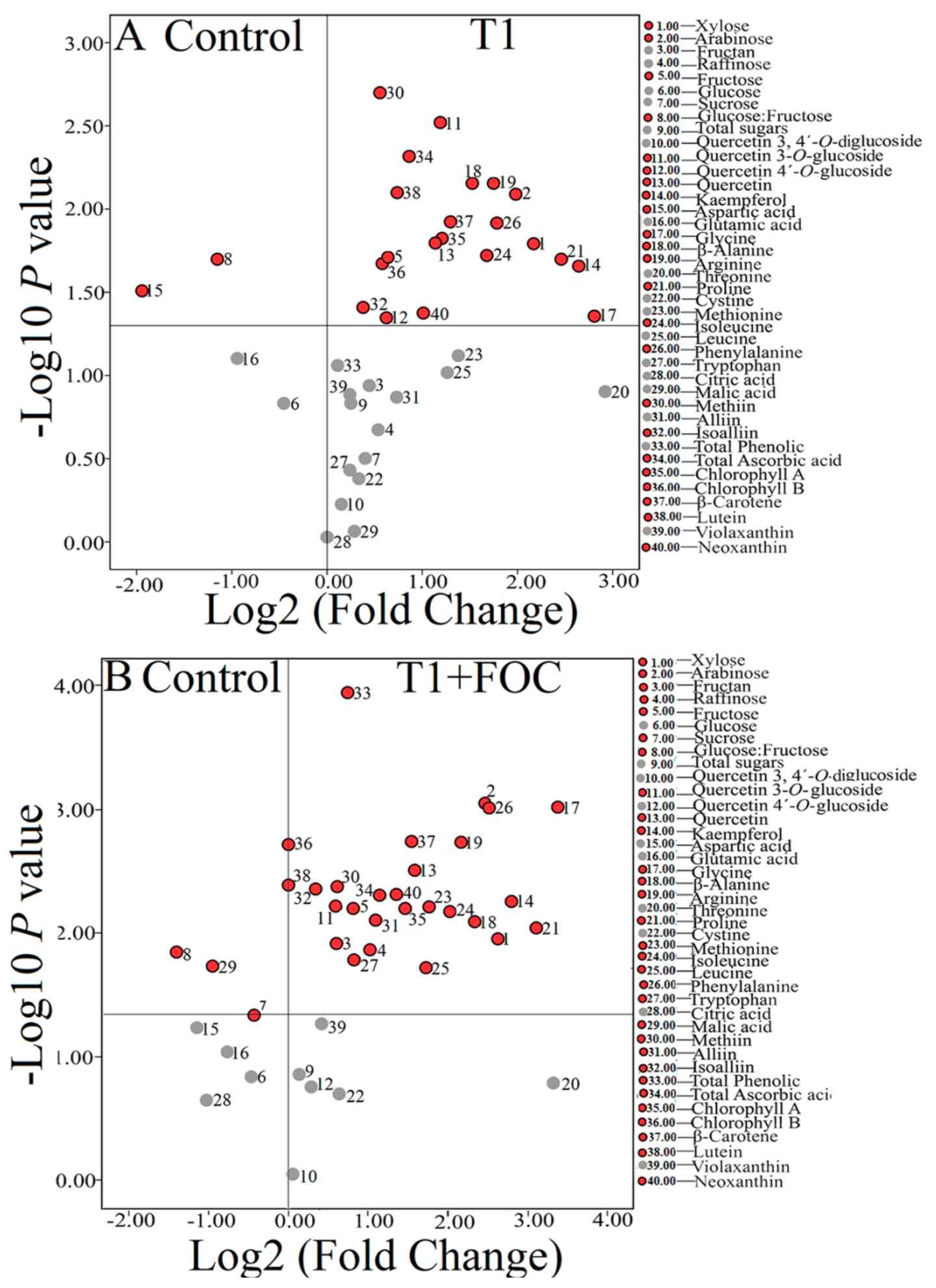

Figure 3 


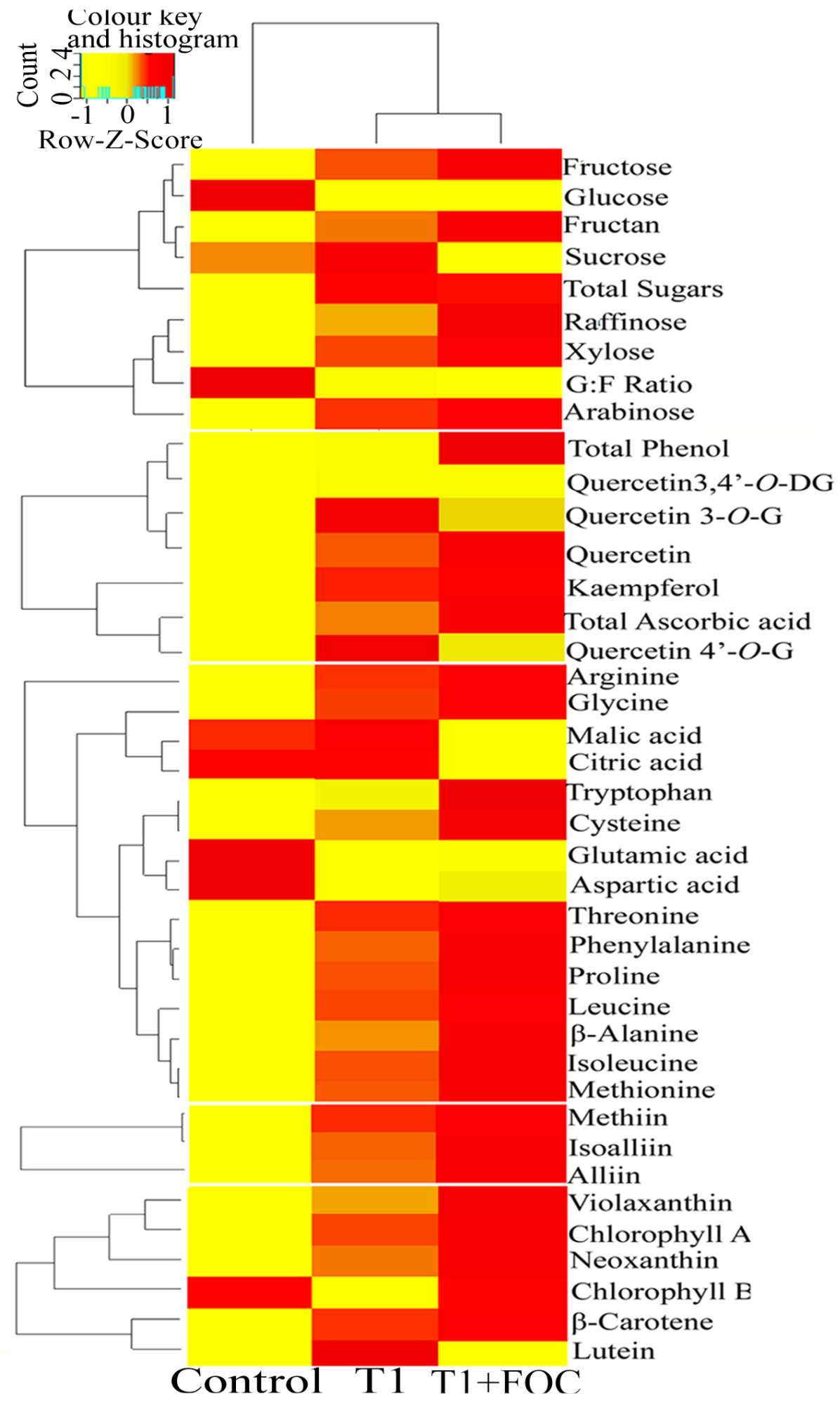

Figure 4 


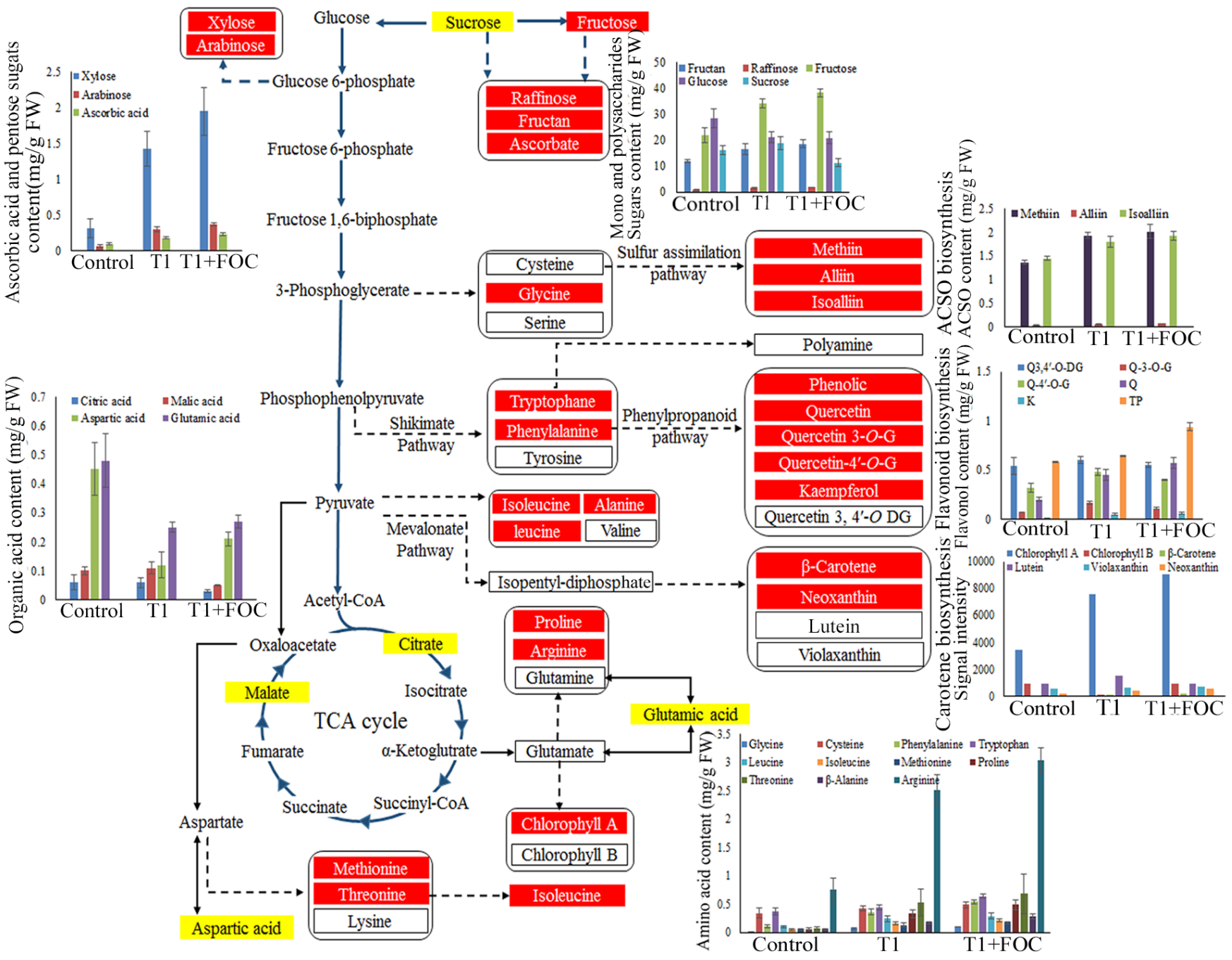

\section{Figure 5}




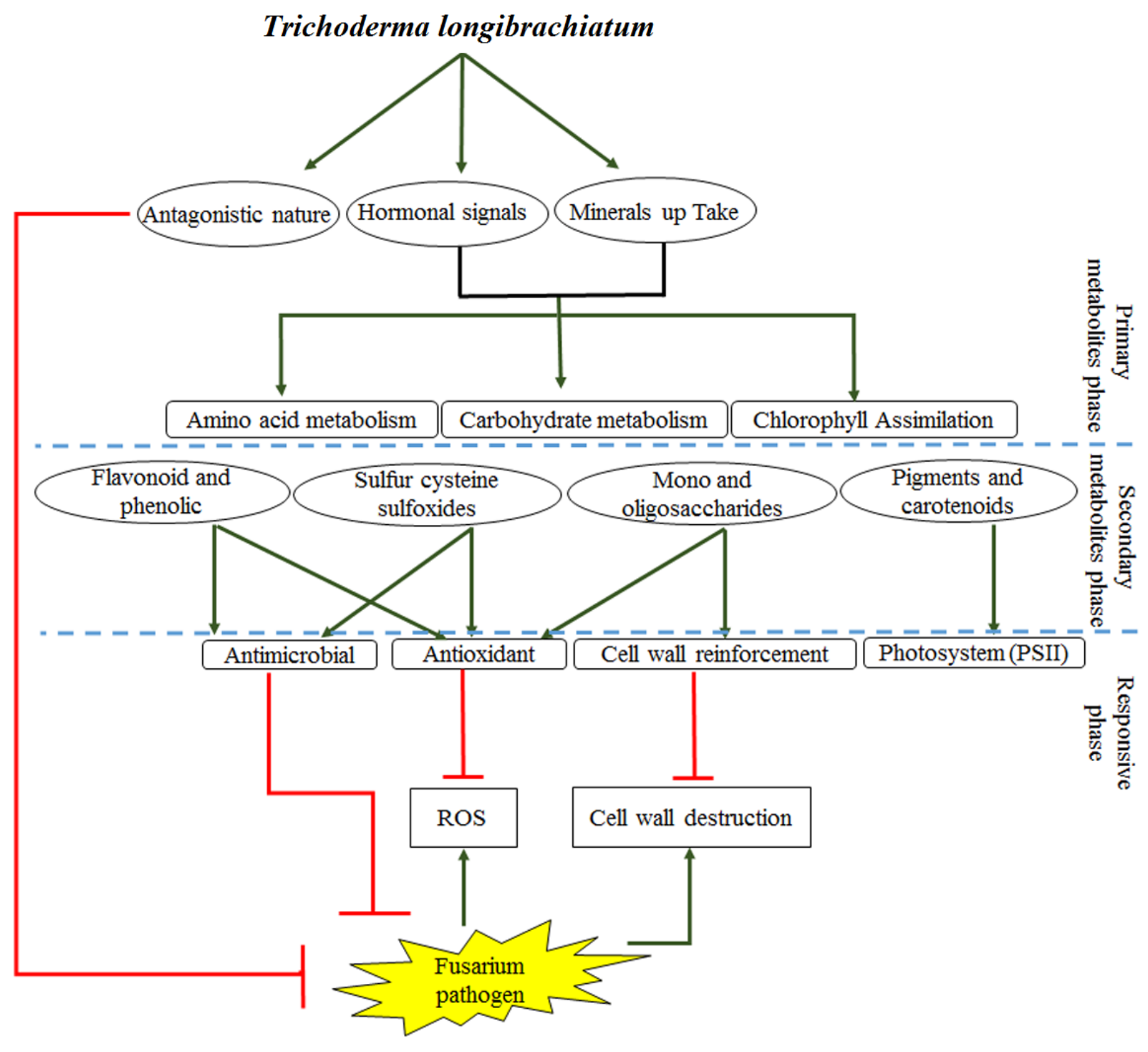

\section{Figure 6}

